\title{
Impact of tumor heterogeneity on disease-free survival in a series of 368 patients treated for a breast cancer
}

\author{
Myriam Oger ${ }^{1 *}$, Mohamed Allaoui ${ }^{2}$, Nicolas Elie ${ }^{3}$, Jacques Marnay ${ }^{2}$, Paulette Herlin, Benoît Plancoulaine ${ }^{1}$, \\ Jacques Chasle ${ }^{1}$, Véronique Becette ${ }^{1}$, Catherine Bor-Angelier ${ }^{1,2}$ \\ From 11th European Congress on Telepathology and 5th International Congress on Virtual Microscopy \\ Venice, Italy. 6-9 June 2012
}

\section{Introduction}

Tumor heterogeneity [1-4] is an old concept but its impact on the cancerogenesis process is poorly understood. Breast cancer is a noteworthy model for its frequency, and for the diversity of its phenotypes and of its evolution. This study examines the influence of the heterogeneity of tumor proliferation on disease-free survival of patients with a breast carcinoma.

\section{Material and methods \\ Histological slides}

The study involved a series of 368 patients from the François Baclesse Cancer Centre (Caen) treated for a breast carcinoma between 1991 and 1995, whitout neoadjuvant therapy and with a follow-up of more than 15 years. The table 1 contains the description of the series.

Histological sections, representative of each tumor, have been stained with the anti-phosphohistone-H3 antibody (PHH3: Ser10, MILLIPORE ${ }^{\circledR}$, dilution 1/600) $[5,6]$. With this specific immuno-stain, cells presenting mitosis figures are more easily identifiable (Figure 1).

\section{Acquisition}

Histological slides have been scanned with a high resolution slide scanner to obtain virtual slides with a final resolution of $0.5 \mu \mathrm{m}$ (ScanScope ${ }^{\circledR}$ CS from Aperio Technologies (20x NA 0.7 objective). The true color images obtained (color RGB 24 bits) have been saved in the tiled pyramidal TIFF file format.

\footnotetext{
* Correspondence: myriam.oger@gmail.com

'Imagin' Team of EA 4656 in François Baclesse Cancer Centre, 3 avenue du Général Harris, 14076 Caen, France

Full list of author information is available at the end of the article
}

Region of interest (ROI)

Before the automatic image analysis, the user can discard "normal" tissue surrounding the tumor by drawing a region of interest on the high resolution virtual slide with the Aperio ImageScope ${ }^{\circledR}$ software.

\section{Image processing}

The image processing was performed in two steps on a personal computer with a $1.6 \mathrm{GHz}$ Pentium IV processor and a $1 \mathrm{~GB}$ of random access memory (RAM). The first step being a sub-sampling of virtual slide done with a specific algorithm 'Daubechies' second moment orthogonal wavelet decimation developed in $\mathrm{C}++$ language which creates a low resolution image of the virtual slide (divided by 8 : from $0.5 \mu \mathrm{m}$ to $4 \mu \mathrm{m} /$ pixels). In a second step, the low resolution image is automatically processed thanks to chaining operators of image analysis toolbox software (Aphelion, ADCIS).

In addition to estimating the frequency of mitotic figures, the program detects "hot spots" and measures 9 features representing the tumor heterogeneity, including the Haralick texture features and Fisher's index. The zones of influence of each stained nuclei have been determined using Voronoï's pavement principle. When nuclei are close, the size of pavements is small, highlighting the "hot spots".

\section{Feature selection}

A principal component analysis has been done in order to select the most relevant features.

\section{Statistic analysis}

These features have been statistically analyzed, combined with classic clinic-pathological prognostic factors 


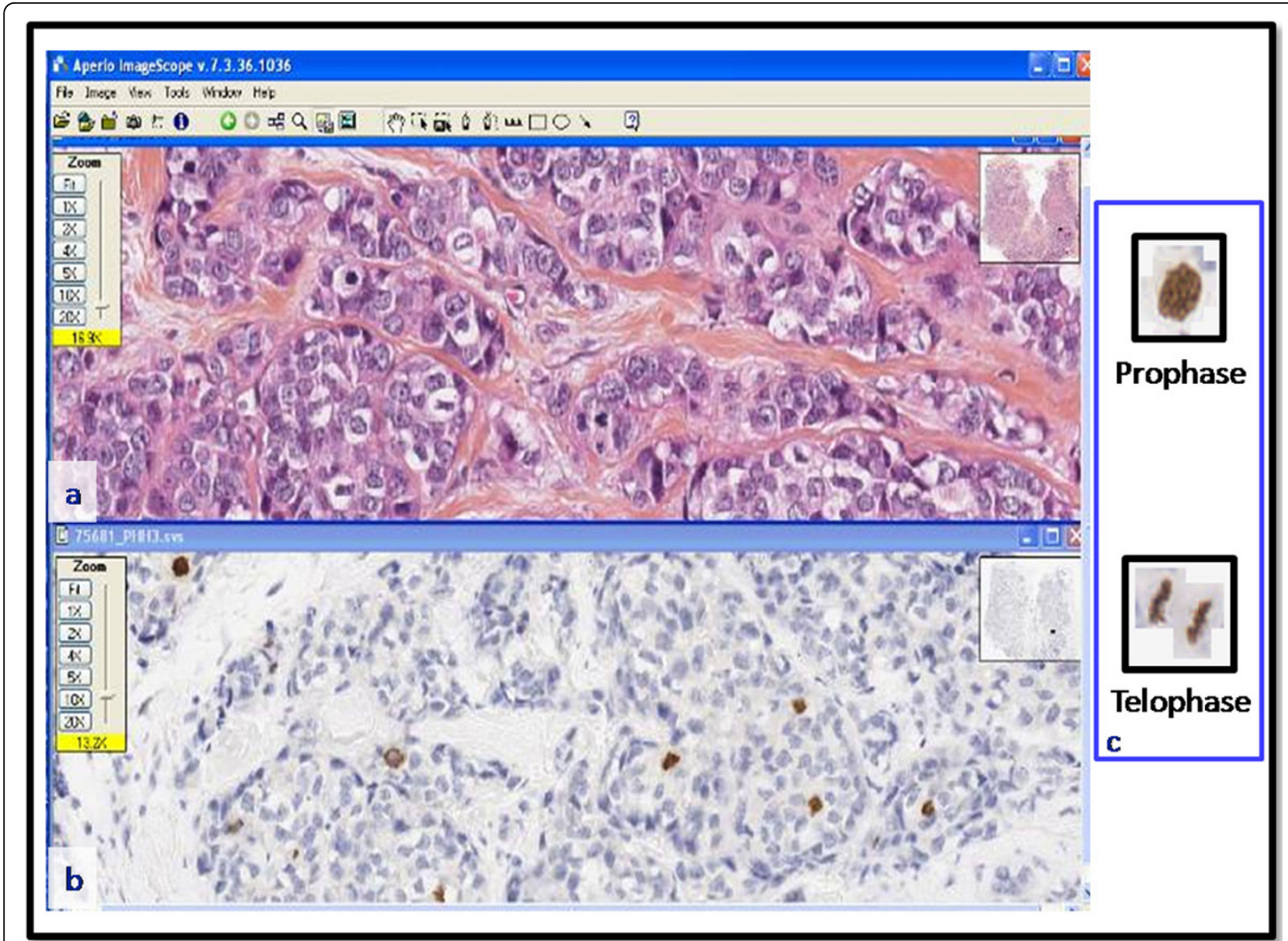

Figure 1 dyes used to stain the histological sections. a: histological slide stained with HES; $\mathbf{b}$ : histological slide of the same case immunohistochemically stained with PHH3 [6-8] (anti-phosphohistone-H3 antibody); c: thanks to this specific immunohistochemical, identification of cells with mitosis figures, from prophase to telophase, is improved.

(age, tumor size, grading, mitotic index, vascular emboli and metastatic lymph nodes).

\section{Results}

\section{Principal component analysis}

Thanks to the principal component analysis (PCA) 4 features representing tumor heterogeneity have been chosen then combined into three new features: CP1, $\mathrm{CP} 2$ and $\mathrm{CP} 3$, corresponding to the three principal directions of the PCA.

The four selected features are:

- 2 Haralick's texture indexes (correlation and energy);

- Fisher's index;

- variance of the size of Voronoï pavements.

The variance of the size of Voronoï pavement (named Voronoï) and the Fisher's index are regional features whereas the Haralick's texture indexes are local features. Indeed, Voronoï and Fisher features are "cutting" the tissue into pieces and analyzing each of them compared to the others, whereas Haralick is dealing with relations between neighbor pixels, each pixel representing a cell at this resolution.

\section{Prognostic study}

In the analysis of prognostic factors, disease free survival was used as the end point.

\section{Univariate statistical analysis (DFS)}

Univariate analysis of disease free survival was performed with the features of age, tumor location, initial tumor size, pathologic lymph node status $(\mathrm{N})$, histological type, SBR grade, mitotic index, vascular emboli, metastatic lymph nodes and hormone receptor status. The results are shown in Table 1 for usual features, in Table 2 for heterogeneity features.

The CP2 feature correlated highly with disease free survival, whereas the variance of the Voronoï pavements was borderline significant.

\section{Multivariate statistical analysis (Cox)}

The above features that correlated with disease free survival in univariate analysis were combined with 
Table 1 Univariate Analysis of Disease Free Survival 368 Eligible Patients. In grey: Follow up (2011)

\begin{tabular}{|c|c|c|}
\hline Variable & No. of patients & $P$ value \\
\hline \multicolumn{3}{|l|}{ Age } \\
\hline Mean $=58.7 \mathrm{yr}$ & & 0.400 \\
\hline \multicolumn{3}{|l|}{ Menopauses } \\
\hline Yes & $237(65 \%)$ & \\
\hline No & $124(34 \%)$ & \\
\hline \multicolumn{3}{|l|}{ Localization } \\
\hline Right breast & $176(47.8 \%)$ & \\
\hline Left breast & $187(50.8 \%)$ & \\
\hline Synchronous bilateral & $5(01.4 \%)$ & \\
\hline \multicolumn{3}{|l|}{ Tumor size } \\
\hline Mean $=25 \mathrm{~mm}$ & & 0.010 \\
\hline \multicolumn{3}{|l|}{ Surgery } \\
\hline Tumorectomy & $212(57.6 \%)$ & \\
\hline Mastectomy & $141(38.3 \%)$ & \\
\hline Biopsy & $15(04.1 \%)$ & \\
\hline \multicolumn{3}{|l|}{ Excision quality } \\
\hline Satisfying & $202(57.2 \%)$ & \\
\hline Unsatisfying & $47(13.3 \%)$ & \\
\hline Unspecified & $104(29.5 \%)$ & \\
\hline \multicolumn{3}{|l|}{ Histological type } \\
\hline ICC & $297(80.71 \%)$ & \\
\hline ILC & $37(10.05 \%)$ & \\
\hline \multicolumn{3}{|l|}{ SBR grade } \\
\hline Grade 1 & $50(14 \%)$ & \\
\hline Grade 2 & $180(49 \%)$ & 0.002 \\
\hline Grade 3 & $137(37 \%)$ & \\
\hline \multicolumn{3}{|l|}{ Mitotic index $\left(/ 1.7 \mathrm{~mm}^{2}\right)$} \\
\hline Mean $=10$ mitosis & & $<0.0001$ \\
\hline \multicolumn{3}{|l|}{ Tumor vascular emboli } \\
\hline Yes & $293(79.6 \%)$ & \\
\hline No & $75(20.4 \%)$ & \\
\hline \multicolumn{3}{|l|}{ Lymph node metastasis } \\
\hline Yes & $153(44 \%)$ & $<0.0001$ \\
\hline No & 195 (56\%) & \\
\hline \multicolumn{3}{|c|}{ Hormone receptor status (at least 1) } \\
\hline Yes & $265(73 \%)$ & 0.030 \\
\hline No & $98(27 \%)$ & \\
\hline
\end{tabular}

Visceral or lymph node (other than axillary) metastasis

$$
\begin{array}{ll}
\text { Yes } & 136(37 \%) \\
\text { No } & 232(63 \%)
\end{array}
$$

Local recurrence

$\begin{array}{lr}\text { Yes } & 66(18 \%) \\ \text { No } & 302(82 \%)\end{array}$

Oncological event (Metastasis and/or local recurrence)

Yes $\quad 157(42.5 \%)$

No $\quad 211(57.5 \%)$

Death

Yes $\quad 90(24.46 \%)$

No $\quad 278(75.54 \%)$
Table 2 Results of the univariate analysis

\begin{tabular}{cc}
\hline Variables & P value \\
\hline Voronoï & 0.040 \\
\hline Normalized variance of density & 0.170 \\
\hline Energy (Haralick) & 0.090 \\
\hline CP1 & 0.500 \\
\hline CP2 & 0.016 \\
\hline CP3 & 0.670
\end{tabular}

clinic-pathologic factors and included in the multivariate analysis. Cox's regression analysis highlighted 3 independent prognostic factors: tumor heterogeneity feature $\mathrm{CP} 2$ $(R R=1.46 ; p=0.03)$, mitotic index $(R R=1.71 ; p=$ $0.004)$ and lymph node metastasis $(R R=2.20, p<$ 0.0001 ) correlated highly with disease free survival.

The construction of this model has individualized 3 groups of patients: 0 factor, 1 or 2 factors and 3 poor prognostic factors (mitotic index $>10$, lymph node metastasis in the axillary dissection, upper tercile of $\mathrm{CP} 2$; $\mathrm{p}<0.0001$ ).

Disease free survival according to this model is shown in Figure 2.

\section{Discussion and conclusion}

To characterize tumor heterogeneity in the presented series of breast cancer, 9 features were computed. 4 nonredundant of them have been selected by principal component analysis (PCA).

PCA was also used to create 3 new composite features: $\mathrm{CP} 1, \mathrm{CP} 2$ and $\mathrm{CP} 3$, corresponding to the 3 principal directions of the PCA.

The univariate analysis made for each feature from image analysis has first highlighted that only the combination CP2 and Voronoï's feature had a prognostic value. It has to be noted that a high value of heterogeneity index is associated with a poor prognosis.

In multivariate analysis, $\mathrm{CP} 2$ was found to be an independent prognostic feature just like the mitotic index and the lymph node status. The lymph node status is a well-known clinical factor; the two other features are intrinsic factors of tumor growth, at cellular level for mitotic index and at the tissue level for heterogeneity.

Surprisingly, age, tumor size, Scarff and Bloom Grade and hormone receptor status are of secondary importance compared to these 3 features.

This result encourages to confront the heterogeneity feature CP2 to clinic information, such as recent or late oncologic event or the nature locoregional or distant visceral of the recurrence, and to the absence of lymph node metastasis. 


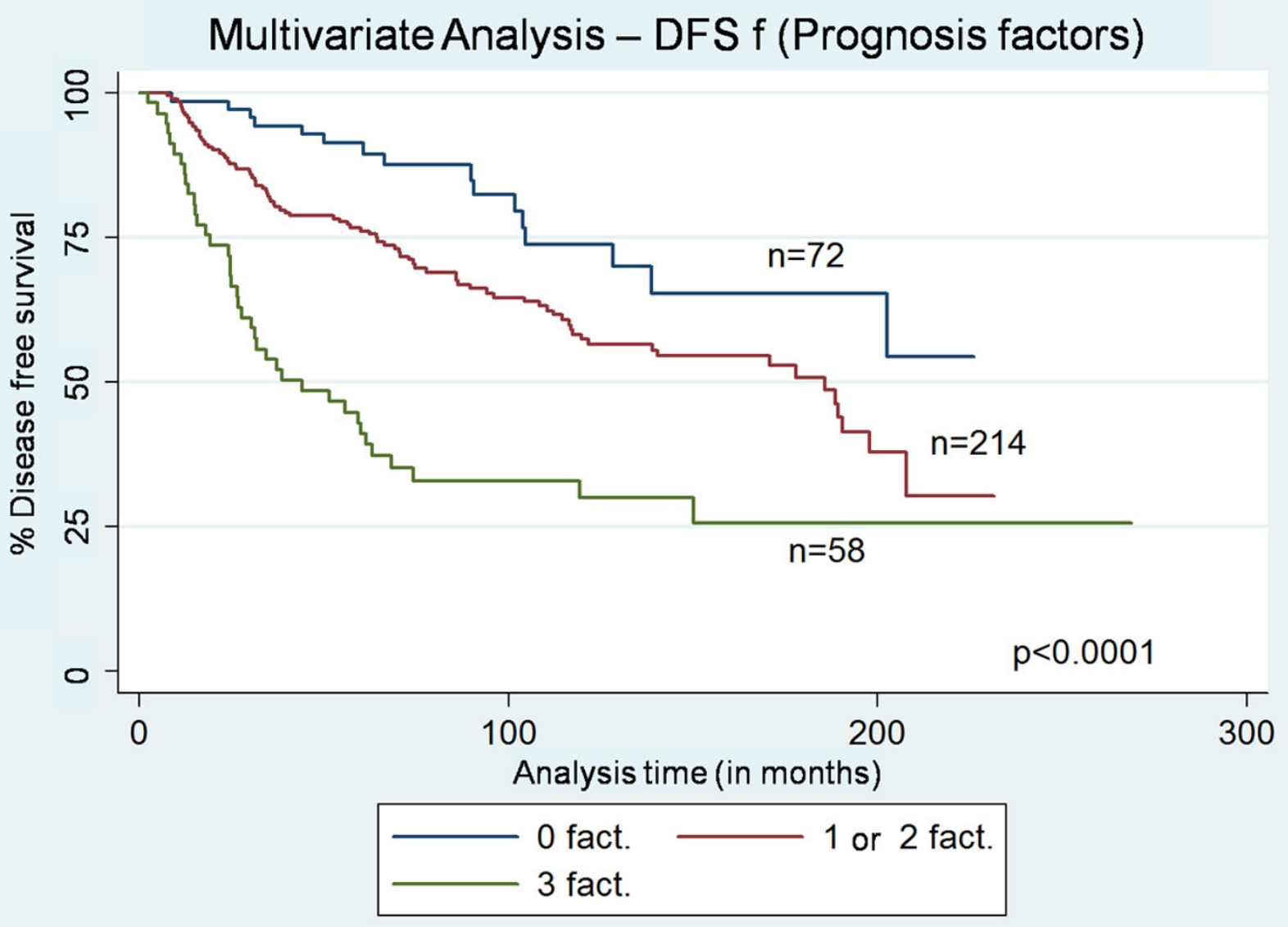

Figure 2 Model build using the results of the multivariate analysis. Multivariate analysis highlighted 3 independent prognostic factors: tumor heterogeneity (CP2), mitotic index, lymph node metastasis. The construction of this model has individualized 3 groups of patients: 0 factor, 1 or 2 factors and 3 poor prognostic factors (mitotic index $>10$, lymph node metastasis in the axillary dissection, upper tercile of CP2; $\mathrm{p}<$ $0.0001)$.

Competing interests

The authors declare no competing interests.

\section{Authors' contributions}

$\mathrm{MO}, \mathrm{MA}, \mathrm{NE}, \mathrm{JM}, \mathrm{PH}, \mathrm{BP}$ and $\mathrm{CB}$ defined the research theme, analyzed the data and interpreted the results. $\mathrm{NE}, \mathrm{PH}$ and $\mathrm{BP}$ designed and carried out experiments for the computation the heterogeneity features. JC, VB and CB collected the data for classical clinic-pathological prognosis factors such as histological type and grade of the tumor, size or mitotic index. VB drawn the Regions of Interest for all the images. MO carried out the experiments to select the most relevant heterogeneity features and create the new CP2 feature. JM carried out all the statistical analyses. MO and MA wrote the paper.

All authors read and approved the final manuscript.

\section{Authors' details}

'Imagin' Team of EA 4656 in François Baclesse Cancer Centre, 3 avenue du Général Harris, 14076 Caen, France. ${ }^{2}$ Pathology laboratory, François Baclesse Cancer Centre, 14076 Caen, France. ${ }^{3}$ Plateau d'Histo-Imagerie Quantitative, SF ICORE, CMABIO, University of Caen Basse-Normandie, 14076 Caen, France.

Published: 30 September 2013

\section{References}

1. Dodd LG, Kerns B-J, Dodge RK, Layfield LJ: Intratumoral Heterogeneity in Primary Breast Carcinoma: Study of Concurrent Parameters. Journal of Surgical Oncology 1997, 64:280-288.

2. Sharifi-Salamatian V, de Roquancourt A, Rigaut JP: Breast carcinoma, intratumour heterogeneity and histological grading, using geostatistics. In Analytical Cellular Pathology. Volume 20. IOS Press:0921-8912 2000:83-91.

3. Bertucci F, Birnbaum D: Reasons for breast cancer heterogeneity. Journal of Biology 2008, 7:6.

4. Fisher B, Redmond CK: Evolution of Knowledge Related to Breast Cancer Heterogeneity: A 25-Year Retrospective. Journal of Clinical Oncology 2008, 26(13):2068-2071.

5. Hans F, Dimitrov S: Histone $\mathrm{H} 3$ phosphorylation and cell division. Oncogene 2001, 20:3021-3027.

6. Bossard $\mathrm{C}$, et al: Phosphohistone $\mathrm{H} 3$ labelling for histoprognostic grading of breast adenocarcinomas and computer-assisted determination of mitotic index. J Clin Pathol 2006, 59(7):706-10.

7. Gosme M: Modélisation du développement spatio-temporel des maladies d'origine tellurique, thèse de doctorat. Rennes: Université de Rennes I; 2007, 198.

8. Fisher RA: The use of multiple measurements in taxonomic problems. Ann. Eugenics 1936, 7:179-188. 
9. Marcelpoil R, Usson Y: Methods for the study of cellular sociology: Voronoi diagrams and parametrization of the spatial relationships. J. Theor. Biol 1992, 154:359-369.

10. Haralick RM, Shanmugam K, Dinstein I: Textural features for image classification. IEEE Transaction on Systems, Man and Cybernetics 1973, 3(6):610-621.

\section{doi:10.1186/1746-1596-8-S1-S43}

Cite this article as: Oger et al: Impact of tumor heterogeneity on disease-free survival in a series of 368 patients treated for a breast cancer. Diagnostic Pathology 2013 8(Suppl 1):S43.

Submit your next manuscript to BioMed Central and take full advantage of:

- Convenient online submission

- Thorough peer review

- No space constraints or color figure charges

- Immediate publication on acceptance

- Inclusion in PubMed, CAS, Scopus and Google Scholar

- Research which is freely available for redistribution

Submit your manuscript at www.biomedcentral.com/submit
C Biomed Central 